\title{
An African perspective on the genetic risk of chronic kidney disease: a systematic review
}

\author{
Cindy George ${ }^{1^{*}} \mathbb{D}$, Yandiswa Y Yako ${ }^{2}$, Ikechi G Okpechi ${ }^{3,4}$, Tandi E Matsha ${ }^{5}$, Francois J. Kaze Folefack ${ }^{6,7}$ \\ and Andre P Kengne ${ }^{1}$
}

\begin{abstract}
Background: Individuals of African ethnicity are disproportionately burdened with chronic kidney disease (CKD). However, despite the genetic link, genetic association studies of CKD in African populations are lacking.

Methods: We conducted a systematic review to critically evaluate the existing studies on CKD genetic risk inferred by polymorphism(s) amongst African populations in Africa. The study followed the HuGE handbook and PRISMA protocol. We included studies reporting on the association of polymorphism(s) with prevalent CKD, end-stage renaldisease (ESRD) or CKD-associated traits. Given the very few studies investigating the effects of the same single nucleotide polymorphisms (SNPs) on CKD risk, a narrative synthesis of the evidence was conducted.

Results: A total of 30 polymorphisms in 11 genes were investigated for their association with CKD, ESRD or related traits, all using the candidate-gene approach. Of all the included genes, MYH9, AT1R and MTHFR genes failed to predict CKD or related traits, while variants in the APOL1, apoE, eNOS, XPD, XRCC1, renalase, ADIPOQ, and CCR2 genes were associated with CKD or other related traits. Two SNPs (rs73885319, rs60910145) and haplotypes (G-A-G; G1; G2) of the apolipoprotein L1 (APOL1) gene were studied in more than one population group, with similar association with prevalent CKD observed. The remaining polymorphisms were investigated in single studies.

Conclusion: According to this systematic review, there is currently insufficient evidence of the specific polymorphisms that poses African populations at an increased risk of CKD. Large-scale genetic studies are warranted to better understand susceptibility polymorphisms, specific to African populations.
\end{abstract}

Keywords: Chronic kidney disease, End-stage renal disease, Genetics, Africa

\section{Background}

Chronic kidney disease (CKD) is fast becoming a leading public health issue in Africa, with an estimated prevalence of $14.3 \%$ in the general population, and $36.1 \%$ in high-risk populations [1]. Due in part to increasing rates of type 2 diabetes, hypertension and obesity, the prevalence of CKD continues to rise [2]. However, marked variability in the incidence of CKD between population groups, suggests additional factors contributing to CKD aetiology [3]. Indeed, prevalent end-stage renal disease (ESRD), which is the terminal stage of CKD, is 4-fold higher among African ethnicity as compared to European ethnicity $[4,5]$ and individuals of African ethnicity

\footnotetext{
* Correspondence: cindy.george@mrc.ac.za

${ }^{1}$ Non-Communicable Diseases Research Unit, South African Medical Research Council, Parow Valley, PO Box 19070, Cape Town, South Africa

Full list of author information is available at the end of the article
}

progress faster from moderately decreased kidney function to ESRD [6]; thus highlighting African ethnicity as a contributing risk factor for CKD $[4,5]$.

Over the past decade, through the use of genomewide association studies (GWAS), researchers have identified various genomic regions with common genetic variants associated with CKD traits [7]. However, a limitation of the majority of GWAS's conducted to date is the paucity of studies conducted in individuals of African ancestry and even less in Africans living in Africa [7-10]. Despite, Africa being one of the most ethnically and genetically diverse regions of the world [11], these populations are understudied, with most of the common loci associated with CKD in non-African populations not being replicated in African populations. Though African migrants living in Europe and America are genetically linked with African ancestry $[12,13]$, these

C The Author(s). 2018 Open Access This article is distributed under the terms of the Creative Commons Attribution 4.0 International License (http://creativecommons.org/licenses/by/4.0/), which permits unrestricted use, distribution, and reproduction in any medium, provided you give appropriate credit to the original author(s) and the source, provide a link to the Creative Commons license, and indicate if changes were made. The Creative Commons Public Domain Dedication waiver (http://creativecommons.org/publicdomain/zero/1.0/) applies to the data made available in this article, unless otherwise stated. 
genetic variants cannot be extrapolated to Africans residing in Africa. This is mainly due to genetic admixture of American and European populations, as well as differences in environment, cultural and lifestyles [11]. Accordingly, identification of genetic loci for CKD in African populations will help to advance our understanding of the underpinnings of CKD in individuals of African descent.

There is currently no systematic review evaluating the CKD-associated genes found in African populations residing in Africa. The main purpose of this review is thus to critically evaluate the existing studies on CKD genetic risk inferred by polymorphisms amongst African populations in Africa, and explore the specific effect these genetic loci have on CKD development in the African population.

\section{Methods}

\section{Protocol and registration}

The review was conducted using the Preferred Reporting Items for Systematic Reviews and Meta-Analysis PRISMA framework [14] and HuGENET ${ }^{\mathrm{Tm}}$ HuGE Review handbook [15]. The methods of the analysis and inclusion criteria were specified in advance and documented in a protocol in the PROSPERO database (registration number: CRD42017058440).

Selection of eligible studies, types of studies and sources of information

Relevant studies published until August 2017 were identified through a comprehensive electronic search of major databases such as MEDLINE (via PubMed), EBSCOhost, Scopus, and Web of Science, using an African search filter [16] and without any starting date or language restrictions. Medical Subject Headings (MeSH) terms and Boolean operators, such as AND/ OR/NOT, were used to string terms together (refer to Additional files 1, 2, 3 and 4: Tables S1-S4). Publication bibliographies were searched to further enhance the search strategy.

\section{Data collection}

Two authors (CG and YYY) independently conducted the database searches and sequentially (titles, abstracts and then full texts) screened them for inclusion (Fig. 1). In situations of disagreements between the two authors, a third author (APK) arbitrated for eligibility. The inclusion criteria was that a study had to be an original study

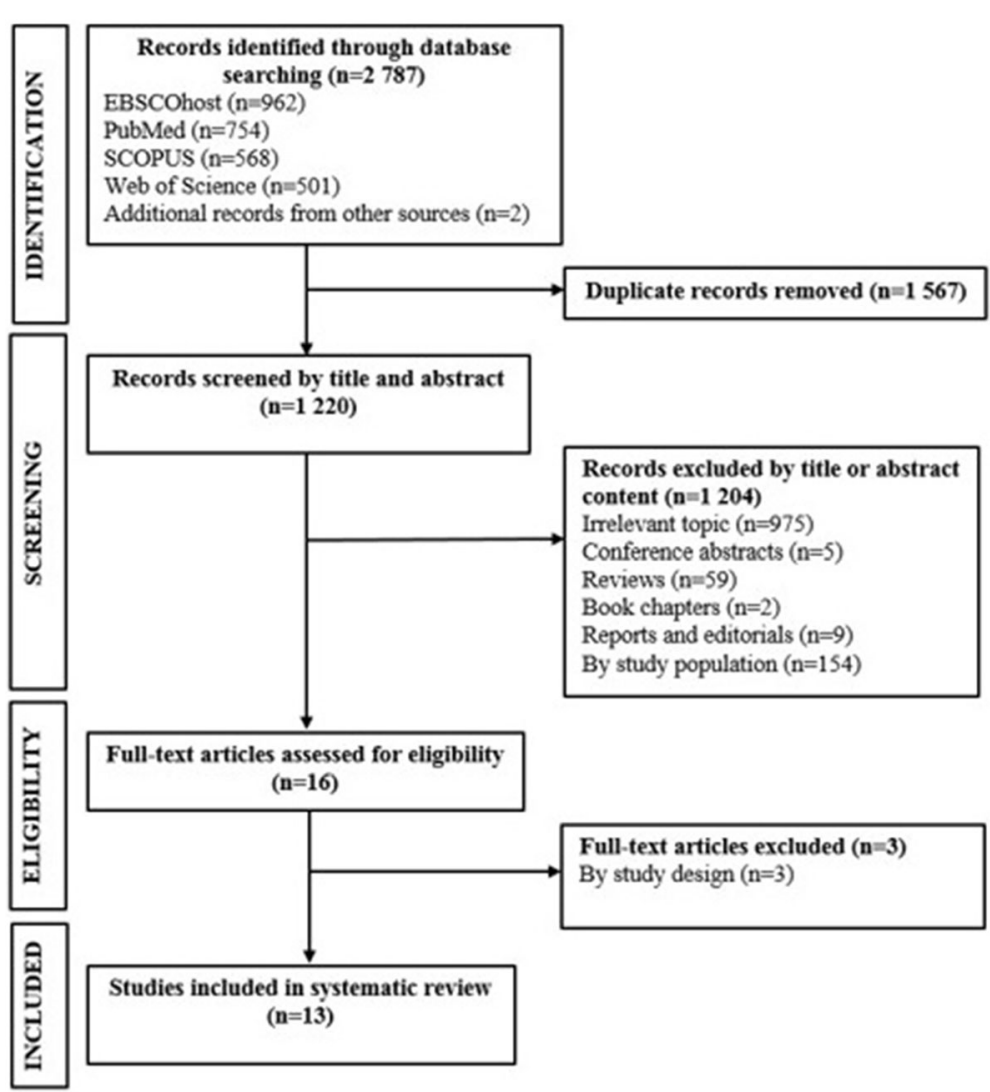

Fig. 1 Selection process for studies included in the systematic review 
containing independent data that were obtained from case-control or cohort studies, which specifically conducted genetic association analyses on African populations residing in Africa. These studies had to report on study population characteristics, methods, CKD or renal traits (such as serum creatinine, estimated glomerular filtration rate (eGFR), urinary albumin excretion), genes and polymorphisms, genotyping technique(s), statistical analyses, and report on allele and genotype frequencies. Studies were excluded if, [1] the conducted analyses were exclusively on migrant African populations, [2] the entire cohort consisted of only high-risk individuals (a population of only type 2 diabetic or hypertensive patients), [3] the study did not report the estimate effects and/or $p$-values, allele and genotype frequencies, and if [4] the study was a meta-analysis, review or any other form of publication that do not have primary data. Full articles were obtained for all abstracts and titles that met inclusion criteria as well as those that certainty of inclusion was unclear. The two authors (CG and YYY) screened the full-text articles, and selected full manuscripts according to the inclusion criteria. Disagreements were resolved through discussion or if consensus were not met, reviewed by a third author (APK). The reasons for excluding studies were also recorded.

\section{Data extraction, assessment and synthesis}

The data extracted from selected articles included the name of the first author and year of publication, study setting and design, population characteristics, genetic models used for measures of association, adjustment (if any) for confounding variables, allele and genotype frequencies, and the study outcome. Data extraction was done by one author (CG), and another author (YYY) verified the accuracy and validity of extracted data. As recommended by Sagoo et al. [17], we assessed the existence of bias considering the following: case definition, population stratification, reporting of methods used (sample size of a study population, genotyping method and its reliability/accuracy, validation of results, statistical analyses). Given the very few studies investigating the effects of the same SNPs on CKD risk across different settings/countries, attempting to pool studies were deemed meaningless, thus, we opted to conduct a narrative synthesis of the evidence instead of a meta-analysis.

\section{Results}

\section{Study selection}

We retrieved 2787 citations (962 from EBSCOhost; 754 from MEDLINE; 568 from SCOPUS; 501 from Web of Science; 2 from publication bibliography) from our searches. Of these, 2771 citations were not eligible for inclusion for the following reasons: duplicate $(n=1567)$ or irrelevant to this review based on the title or abstract $(n=1204)$. Consequently, 16 full-text articles were reviewed and of those, three citations were excluded, based on not meeting the inclusion criteria of this review, resulting in 13 eligible articles retained for the systematic review (Fig. 1).

\section{Characteristics of included studies}

Table 1 describes the characteristics of the genetic studies included in this review. All the studies were conducted between 2009 and 2016 with the vast majority conducted in Egypt $(n=7)$, followed by Nigeria and South Africa $(n=2$, each), and Morocco and Tunisia each with only one reported study on CKD genetic association. Overall, nine studies $(69.2 \%)$ were from three north-African countries [18-26] and the rest from sub-Saharan African countries [27-30]. The study population ranged from 87 to 859 participants per study, with the mean age ranging from 8.7 to 58.9 years and a male predominance in all except the two South African studies, where only $22-23 \%$ were male [27, 28]. Of the thirteen studies included, kidney dysfunction was characterized mainly by an estimated glomerular filtration rate (eGFR) equal to or less than $60 \mathrm{ml} / \mathrm{min} /$ $1.73 \mathrm{~m}^{2}[18,23,25,27,28]$. The remaining studies used other surrogate measures to determine kidney dysfunction, which included ESRD (undergoing haemodialysis) $[19,21,22,24,26]$, elevated serum creatinine levels [20] and a combination of serum creatinine levels greater or equal to $170 \mu \mathrm{mol} / \mathrm{l}$ and dipstick proteinuria greater or equal to 2 [30] or serum creatinine above $1.4 \mathrm{mg} / \mathrm{dl}$ (men) and $1.2 \mathrm{mg} / \mathrm{dl}$ (women) and urinary albumin to creatinine ratio (ACR) above $30 \mathrm{mg} / \mathrm{g}$ [29]. The CKD patients included in these studies were of different aetiologies, reflective of the diversity in nephropathy present in Africa.

Table 2 summarizes the polymorphisms investigated in the included studies. Thirty different polymorphisms (including SNP, indels and repeats) in 11 genes have been studied in various population groups in Africa. Of the polymorphisms investigated by selected studies, only three SNPs of the APOL1 gene (rs73885319, rs60910145, rs71785313) were studied in more than one population group, which included the Yoruba [29] and Igbo [30] tribes of Nigeria and the South African mixed-race population group [27]. The remaining 27 polymorphisms of the MYH9, apoE, AT1R, eNOS, MTHFR, XPD, XRCC1, renalase, $A D I P O Q$ and $C C R 2$ genes were each studied in only one ethnic group. Eight of the included genetic association studies assessed the distribution of allele frequency by formally testing for Hardy-Weinberg equilibrium (HWE), and one study assumed HWE without formal testing [21]. Of those formally tested, only one polymorphism showed a departure from HWE (MYH9 rs4821480), and was 


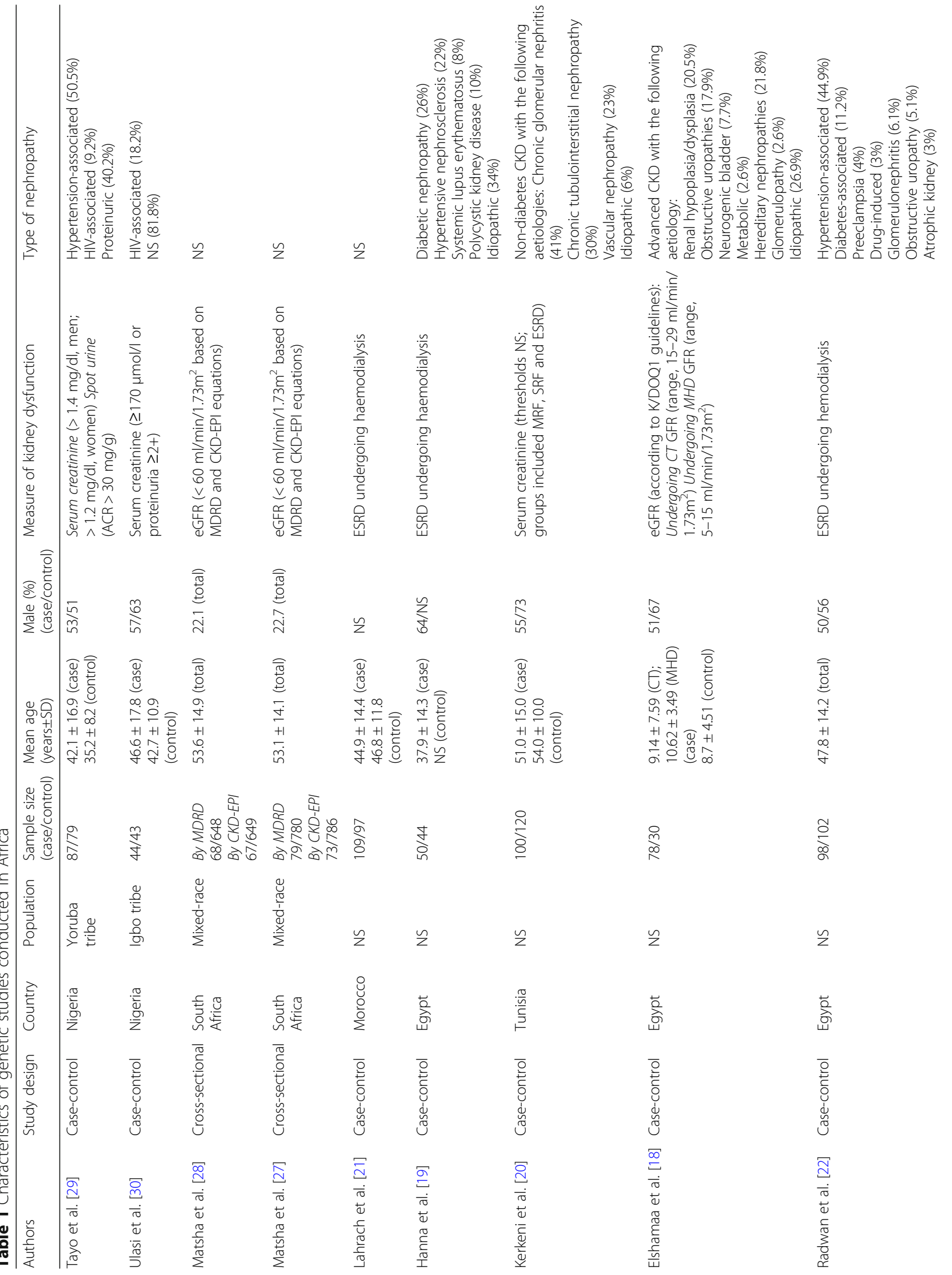




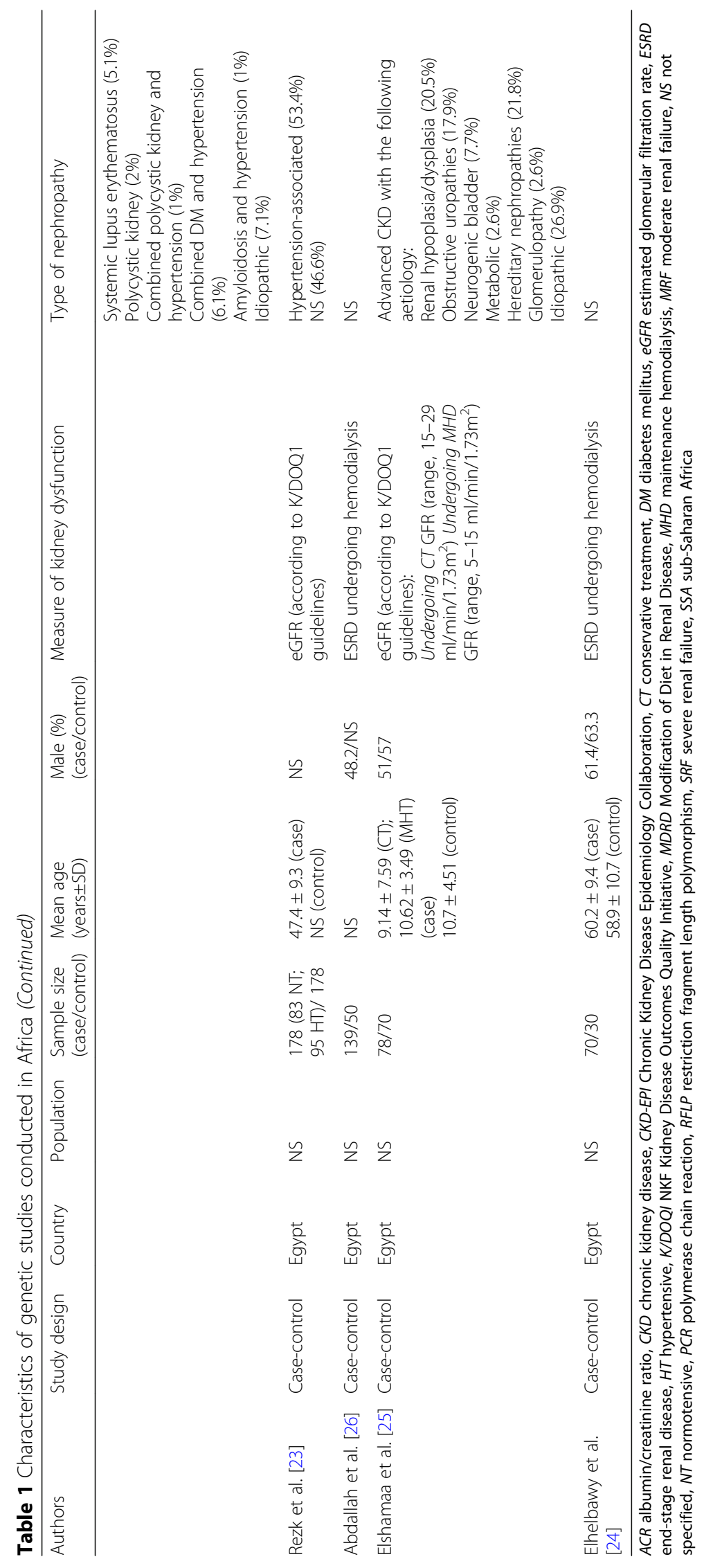


George et al. BMC Medical Genetics

(2018) 19:187

Page 6 of 15

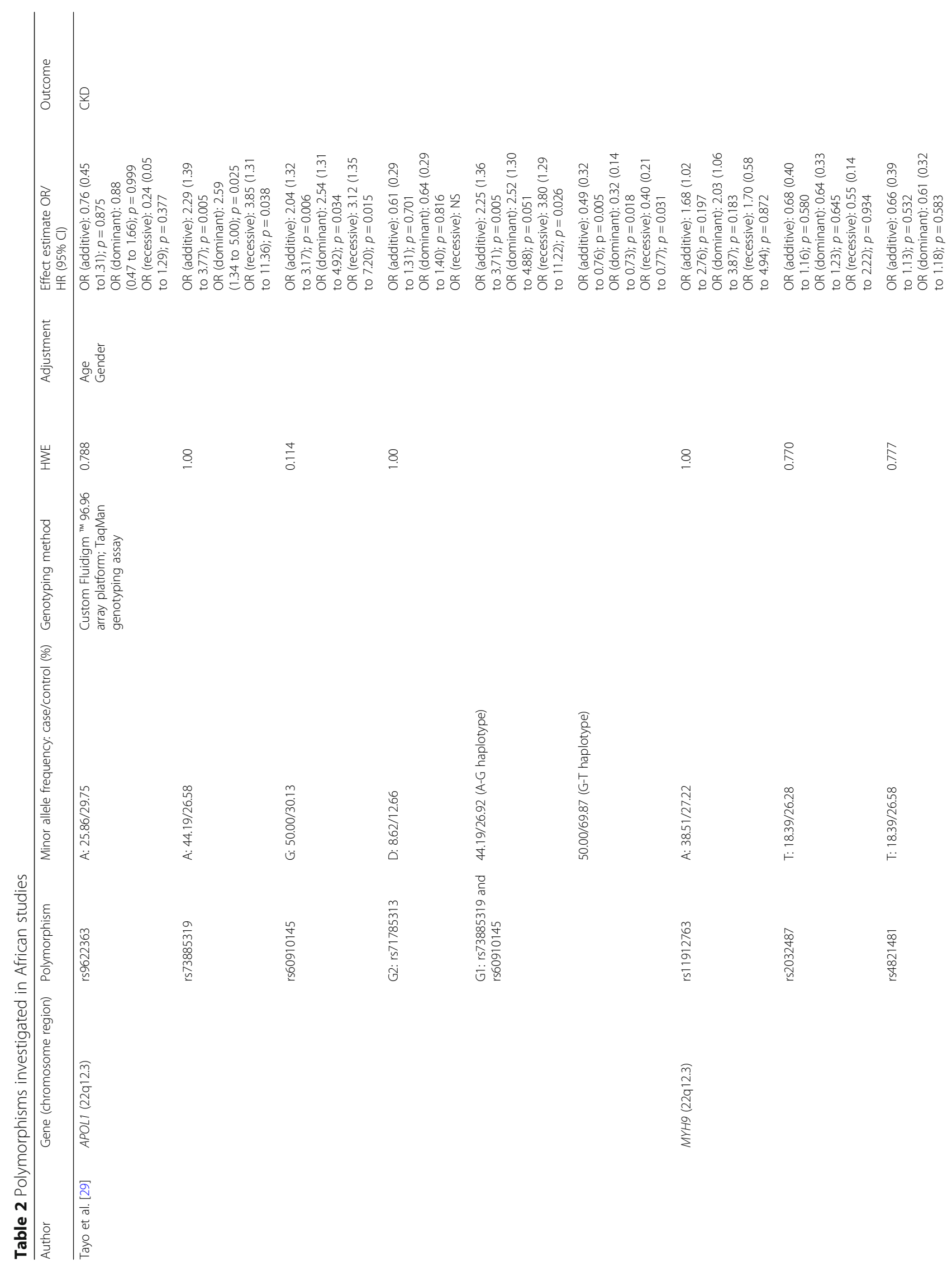


George et al. BMC Medical Genetics (2018) 19:187

Page 7 of 15

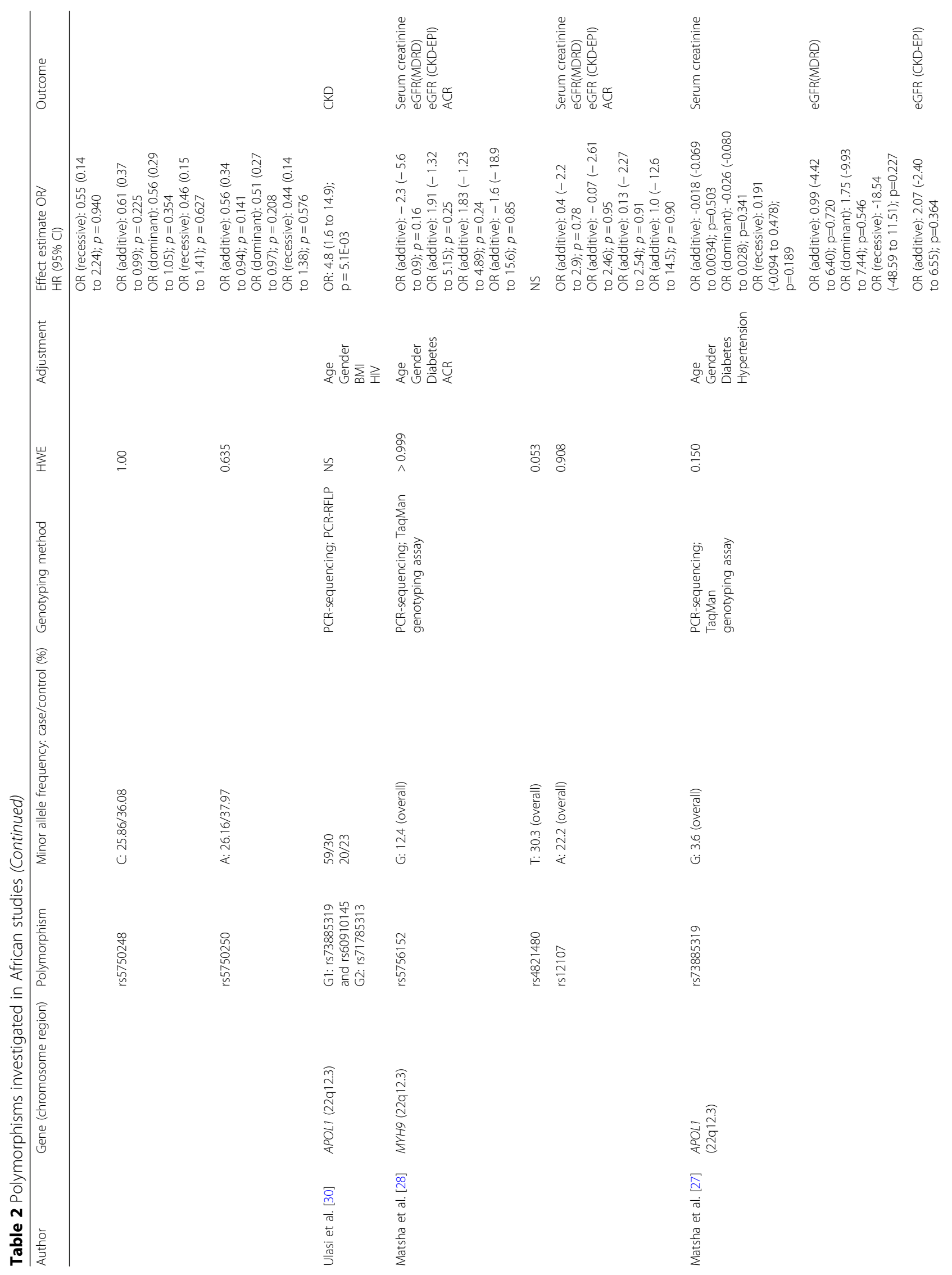


George et al. BMC Medical Genetics

(2018) 19:187

Page 8 of 15

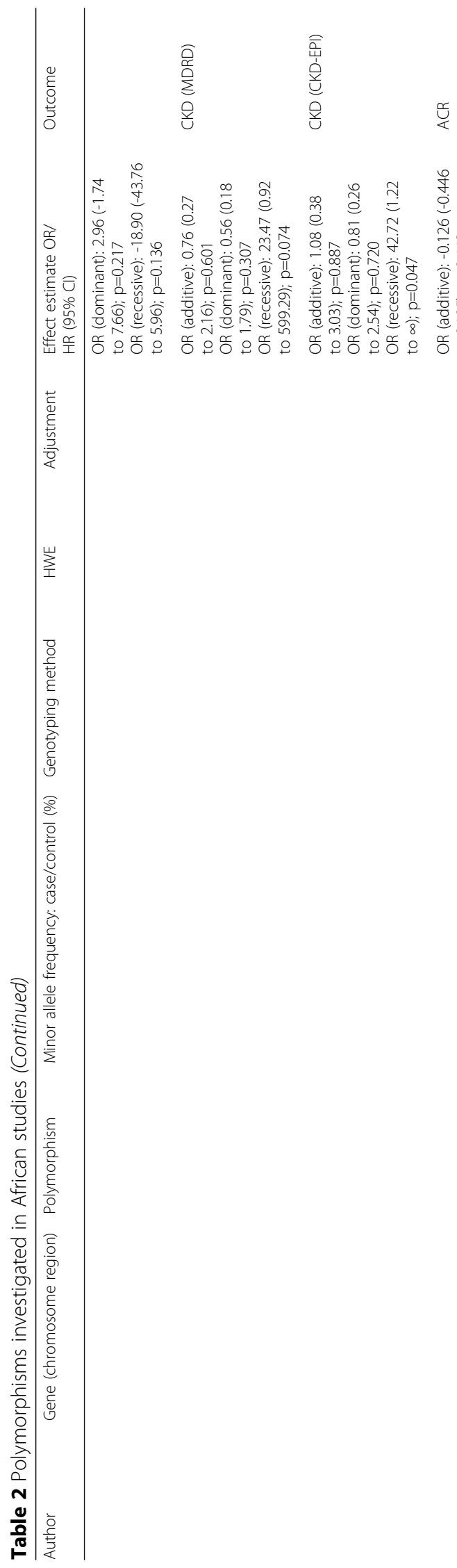

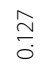

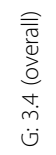

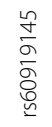




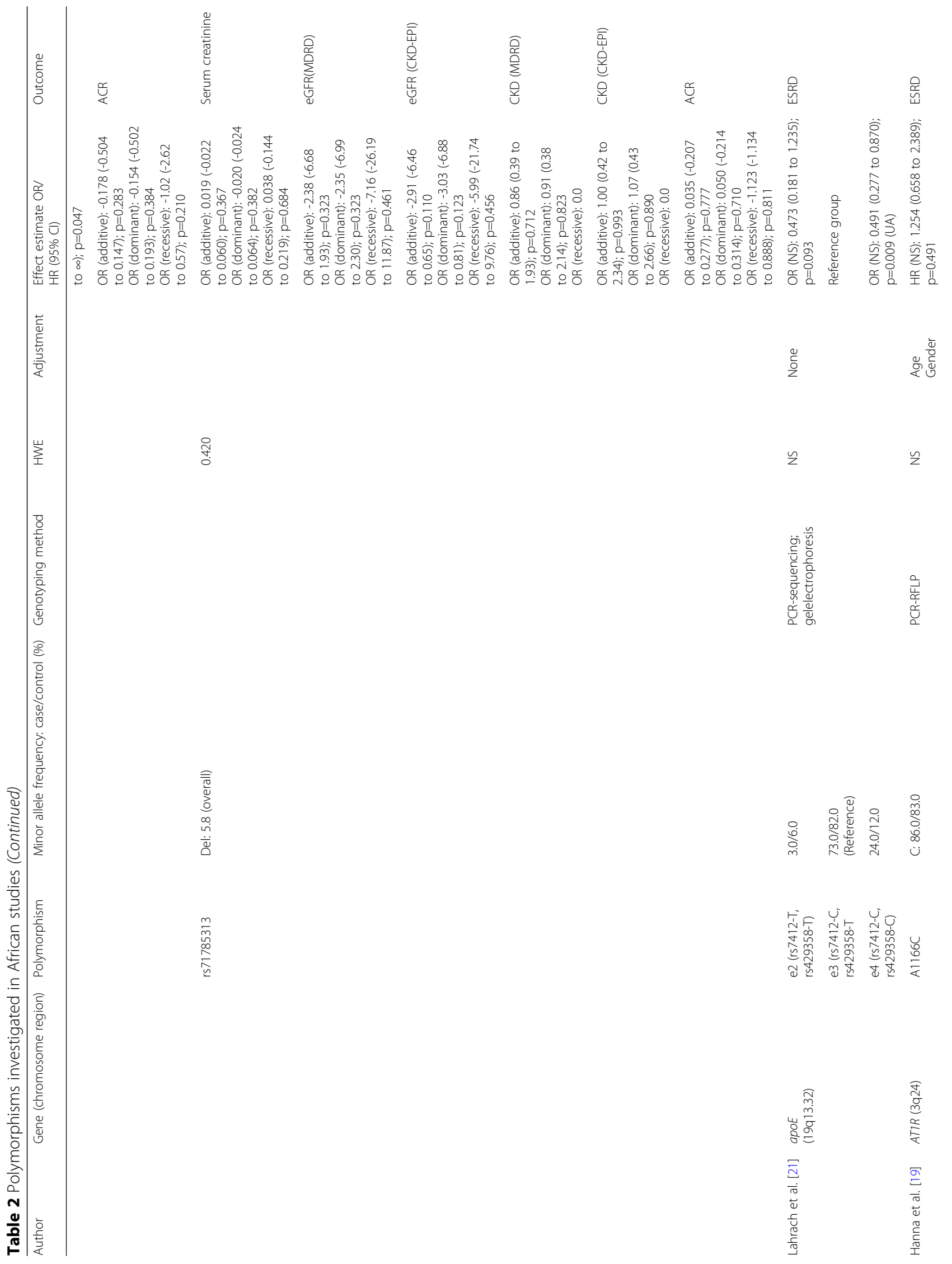




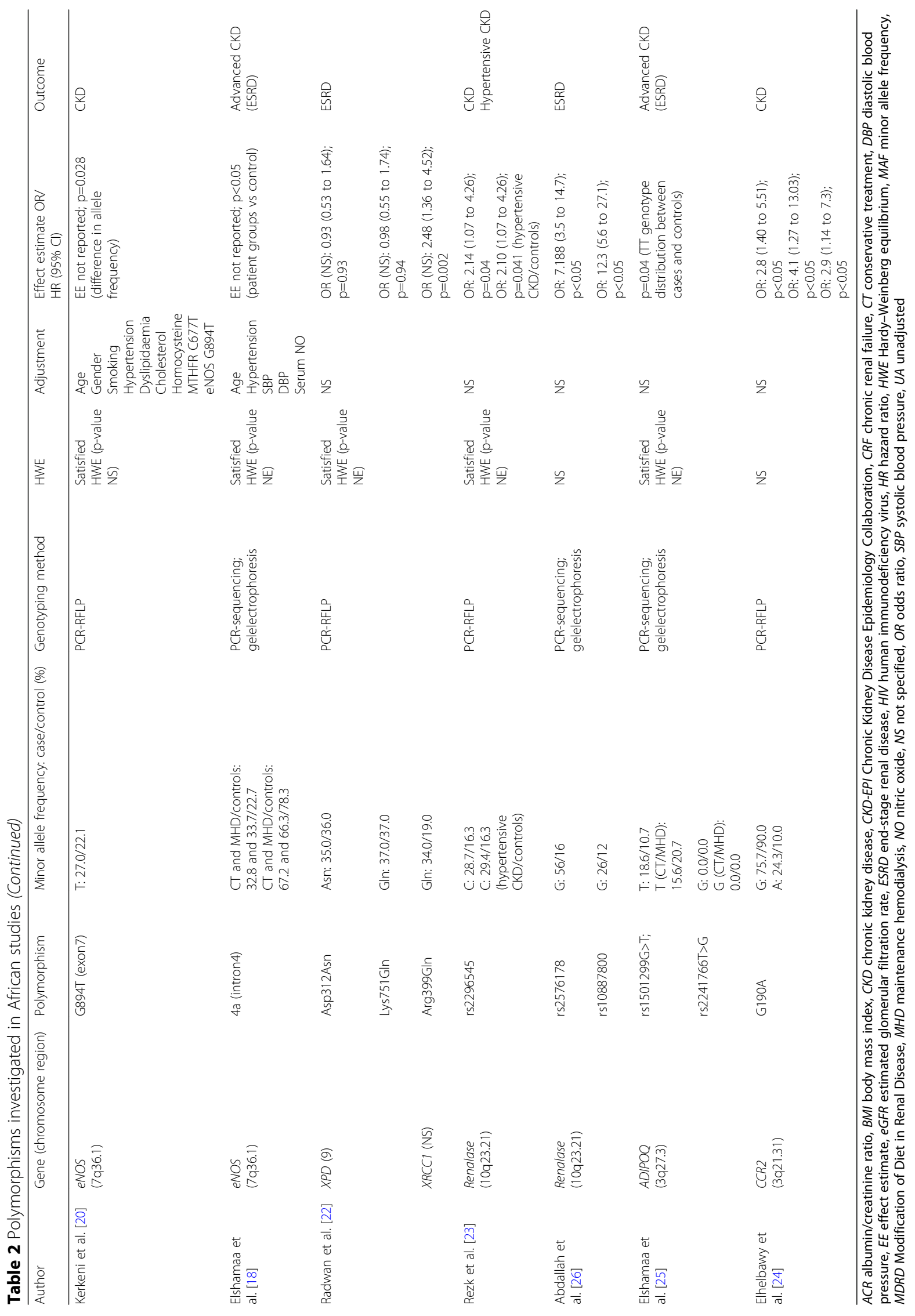


subsequently removed from further association analysis in that study [28]. Adjustment for confounders was not consistent across studies, with six studies not providing information on the degree of adjustment or variables accounted for [21-26]. The remaining seven studies all adjusted for at least age and gender [18-20, 27-30]. In all studies, the genomic DNA was extracted from whole blood samples and genotyped by methods including TaqMan genotyping assays, polymerase chain reaction restriction fragment length polymorphism (PCR-RFLP) and gel-electrophoresis and confirmed by PCR-sequencing.

\section{Association of genetic markers with CKD and related traits}

According to the studies included in this review, some SNP's investigated in the MYH9 [28], AT1R [19], and MTHFR [20] genes failed to predict prevalent CKD, ESRD or related traits (serum creatinine, eGFR and ACR), while variants in the APOL1 [27, 29, 30], apoE [21], eNOS [18, 20], XPD [22], XRCC1 [22], renalase [23, 26], ADIPOQ [31] and CCR2 [24] genes were associated with either prevalent CKD or progression of CKD, ESRD, or other surrogate measures of renal function.

The majority of CKD-associated polymorphisms were conducted in single studies. In a Moroccan population, the e4 allele and the E3E4 genotype of the $a p o E$ gene demonstrated a significant association with ESRD (OR $=0.491 ; p$ $=0.009$ and $\mathrm{OR}=0.316, p<0.001$, e4 and E3E4, respectively) [21]. However, this association was unadjusted for any potential confounder effects. Both Kerkeni et al. [20] and Elshamaa et al. [18] conducted genetic association studies on SNPs in the eNOS gene, adjusting for potential confounders, albeit different population groups and different SNPs. According to Kerkeni et al. [20], the eNOS SNP found in exon 7 (G894 T) was an independent risk factor of severity of CKD $(p=0.01)$ in Tunisian adults. Similarly, Elshamaa et al. [18] found the a-allele in the eNOS (intron 4) gene to predict ESRD in Egyptian children $(p<0.05)$ [18]. Radwan et al. [22] investigated three polymorphisms in the DNA repair genes (XPD and XRCC1) and found that patients with XRCC1-399 $\mathrm{Arg} / \mathrm{Gln}$ genotype had a significantly higher risk of developing ESRD (OR: 2.48; 95\% CI: 1.36-4.52). Furthermore, the haplotypes containing XRCC1-399 Arg/Gln and XPD-312 Asp/Asn as well as XRCC1-399 Arg/Gln and $X P D-751 \mathrm{Lys} / \mathrm{Gln}$ were significantly associated with the development of ESRD (OR: 8.35, 95\%CI: 1.9435.85, $p=0.004$ and OR: 9.22, 95\%CI: 2.14-39.71, $p=$ 0.003, respectively). Two studies, both in Egyptian populations, investigated polymorphisms of the renalase gene [23, 26]. Rezk et al. [23] found that patients with the $\mathrm{CC}$ genotype and carriers of $\mathrm{C}$ allele of the rs2296545 renalase gene were significantly more likely to have prevalent CKD (CC genotype; OR: 4.84, 95\% CI:
1.28-18.2, $p=0.02$ and C-carrier; OR: 2.14, 95\%CI: 1.07-4.26, $p=0.04)$. Abdallah et al. [26], conversely found that carriers of the $G$ allele of the rs2576178 and rs10887800 renalase gene were associated with increased risk of developing ESRD (OR: 7.188, 95\%CI: 3.5-14.7, $p<$ 0.05 and OR: 12.3 , 95\%CI: 5.6-27.1; $p<0.05)$. However, in both studies no adjustments were made for potential confounders. ADIPOQ+276G > T was also investigated for association with ESRD in Egyptian children [31]. This study suggested that the $+276 \mathrm{G}>\mathrm{T}$ allele may indirectly contribute to CKD susceptibility by increasing adiponectin levels $(p=0.04)$. Elhelbawy et al. [24] found a significant association between CCR2-641 and chronic renal failure, particularly the AG genotype $(\mathrm{OR}=2.8,95 \% \mathrm{CI}=1.40-5.51)$, combined AG and GG genotypes $(\mathrm{OR}=4.1,95 \% \mathrm{CI}=$ 1.27-13.03) and A allele $(\mathrm{OR}=2.9,95 \% \mathrm{CI}=1.14-7.3)$.

As seen in Table 2, only polymorphisms in the APOL1 gene were investigated in more than one ethnic group, with the observed association similar in at least two population groups. Indeed, according to the study conducted in the Yoruba tribe of Nigeria [29], two single APOL1 SNPs (rs73885319 and rs60910145) were significantly associated with CKD under all genetic models, with the largest effect under the recessive model (OR: 3.85 and 3.12 for rs73885319, and rs60910145, respectively). Furthermore, due to the linkage disequilibrium (D-prime $=1.00, r^{2}=$ 0.82) between the two SNPs, adjusting for either SNP resulted in no association for the other SNP. Similarly, albeit a different population (mixed-race South Africans), Matsha et al. [27] found the same two single SNPs (rs73885319 and rs60910145) to be associated with prevalent CKD, however only under the recessive model ( $p=$ 0.047) (as measured by the CKD-EPI eGFR equation), even after adjusting for multiple confounders. The study did not observe an association between these single APOL1 SNPs and any of the other surrogate measures of kidney function. Tayo et al. [29] also investigated the adjusted association of APOL1 haplotypes, namely the G-A-G haplotype (rs9622363-rs73885319-rs60910145) and the G1 haplotype (rs73885319 and rs60910145) and found both to be significantly associated with CKD under all models of genetic association (G-A-G, ORs: 2.26; $p=$ 0.005, OR: $2.54 ; p=0.023$ and OR: $3.79 ; p=0.041$ for the additive, dominant and recessive modes; G1, OR: $2.25 ; p$ $=0.006$, OR: $2.52 ; p=0.025$ and OR: $3.80 ; \mathrm{p}=0.041$ for the additive, dominant and recessive modes). Ulasi et al. [30] also conducted a study on the APOL1 G1 haplotype (rs73885319 and rs60910145) and G2 (rs71785313) (Wt:G1 or Wt:G2; G1:G1 or G1:G2 or G2:G2) in the Igbo tribe of Nigeria. This study found no significant effect of the Wt:G1 or Wt:G2 one-copy, but observed a high association between APOL1 two-risk alleles (G1:G1 or G1:G2 or G2:G2) and CKD (OR: 4.8; $p=5.1 \mathrm{E}-03$ ), even after adjusting for various confounders. 


\section{Discussion}

To the best of our knowledge, this is the first comprehensive report of the current evidence on genetic polymorphisms associated with renal disease amongst populations in Africa. This review highlights the lack of genetic association studies conducted within the borders of Africa, despite the known genetic link to CKD and the genetic diversity in Africa.

All the studies included in this review used the candidate gene approach, and amongst these, only MYH9 polymorphisms has been previously investigated by GWAS and showed directional association with CKD in populations elsewhere [10]. Indeed, multiple $M Y H 9$ SNPs have been identified as powerful predictors of non-diabetic kidney disease in African Americans [32], Hispanic-Americans [33], and individuals of European ancestry [34]. However, from this review we found no evidence for the associative role of MYH9 polymorphisms in non-diabetic CKD patients in Africa, as all eight SNPs investigated in populations from Nigeria and South Africa failed to predict prevalent CKD or any other surrogate measure of kidney function [28, 29]. Differences in linkage disequilibrium structure might however explain the lack of genetic association in studies conducted in these African populations. Indeed, previous studies have shown that the G1 and G2 risk variants of the $A P O L 1$ gene are in strong linkage disequilibrium with variants in $M Y H 9$. Indeed, most of the association previously attributed to $M Y H 9$ variants or haplotypes with CKD could be explained by their genetic linkage with $A P O L 1$ polymorphisms in populations of African ancestry residing outside the African continent $[35,36]$. In contrast, the studies included in this review instead observed independent association between four SNPs of the APOL1 gene and with either prevalent CKD, serum creatinine, eGFR or ACR in the included studies [27, 29, 30]. This strong association between $A P O L 1$ polymorphisms and non-diabetic kidney disease found in studies in this review have been replicated in several studies [37-45] since the initial findings reported in African Americans [35, 36]. In addition, as reported in all the above mentioned studies, the risk is mostly conferred by the presence of two copies of the risk alleles, that is, homozygous or compound heterozygous compared to no or one APOL1 risk variant $[35,36]$. It would therefore be of great interest if larger population studies are conducted to ascertain the kidney disease-APOL1 association across African population groups.

Currently, the role of the polymorphisms in the $a p o E$ [21], eNOS [18, 20], XPD [22], XRCC1 [22], renalase [23, 26], $A D I P O Q$ [31] and CCR2 [24] genes in the aetiology of CKD remains controversial and further larger studies should be conducted to confirm these results in population groups within Africa. Certainly, various polymorphisms have been associated, both directly and indirectly, with increased CKD risk in certain populations and decreased CKD risk in others or alternatively have no convincing association. This is true for the polymorphisms investigated in the current review. For example, Lahrach et al. [21] showed that the e4 allele and the E3E4 genotype of the apoE gene demonstrated a strong association with ESRD, similar to a study conducted in a Swedish population [46]. However, a study conducted in African Americans and European Americans showed an opposite effect, with the e4 allele being associated with decreased risk of ESRD progression and decreased risk of prevalent ESRD [47], with no association found between the e4 allele and CKD in Asian populations [48]. The genetic link between eNOS (4a; intron4) and ESRD [18] and CKD severity (G894 T; exon7) [20] have also been studied in two African populations, and in both studies, as in various other studies [49-51], the polymorphisms under investigation were found to be significantly associated with kidney disease. However, this association between polymorphisms of eNOS and kidney disease is not fully elucidated, as the direction and magnitude have been found to differ by population and even within the same population. For example, Bellini et al. [52] demonstrated a strong association between eNOS 4a polymorphism and ESRD risk in a Brazilian population, while Marson et al. [53] found no significant correlation between eNOS 4a polymorphism and ESRD risk in a similar Brazilian population group. The association between DNA repair genes (XPD and XRCC1) and kidney disease is not commonly investigated, and with the exception of the study reviewed in this publication [22], has only been investigated previously in a Turkish population [54]. Both studies showed an association between DNA repair gene polymorphisms and ESRD development. However, the effect estimates amongst the African population were higher than that reported in the Turkish population. From the included studies, it is evident that investigating regional differences in the relationship between genes and CKD risk within Africa has relevance, considering the genetic diversity among ethnic population groups in the continent [55].

Our study has some limitations, which include the small number of existing studies, which precluded statistical analysis by means of meta-analysis. Furthermore, as a result of existing genetic association studies not always reporting on key methodological information that includes testing the HWE, the sample size/power calculations, clear description of controls, consideration and correction for population stratification, as well as the levels of adjustment, it is difficult to draw definitive inferences from these studies. In addition, the sample size of the included studies was much smaller than other studies conducted outside of Africa, thus as a result it 
is possible that with larger sample sizes, additional previously proposed candidate genes may have reached statistical significance. Indeed, with the largest included study comprising 859 participants [27], it is highly likely that most existing studies on the genetics of kidney disease in Africa have been underpowered to replicate existing loci or estimate effects with precision. Furthermore, the majority of included studies were conducted in Egyptian populations, thus not covering all the scope of genetic variations that exist on the African continent. The age range, which varied from approximately 9-60 years, and the range of covariates included in adjustment of the estimates of association also differed substantially across studies and could possibly affect between-studies comparisons. In addition, since we had no access to individual participant data, refined analyses and accounting for potential confounders and other types of bias, could not be executed. However, despite the shortcomings of this review, the strength resides in the fact that, according to our knowledge, this is the first study to systematically and comprehensively review the existing data on genetic association studies of CKD in the context of Africa.

\section{Conclusion}

The putative genetic risk factors that have emerged from current data represent the most promising kidney disease susceptibility genes described to date in populations within Africa. However, larger-scale genetic association studies are needed to further expand our knowledge of the underlying genetic mechanisms of kidney disease among populations within Africa.

\section{Additional files} Additional file 1: Table S1. Medline (Pubmed) search strategy (from
inception to August 2017). (DOCX $20 \mathrm{~kb}$ )

Additional file 2: Table S2. SCOPUS search strategy (from inception to August 2017). (DOCX 20 kb)

Additional file 3: Table S3. EBSCOhost search strategy (from inception to August 2017). (DOCX $20 \mathrm{~kb}$ )

Additional file 4: Table S4. Web of Science search strategy (from inception to August 2017). (DOCX $20 \mathrm{~kb}$ )

\section{Abbreviations}

ACR: Albumin to creatinine ratio; ADIPOQ: Gene encoding adiponectin; apoE: Gene encoding apolipoprotein E; APOL1: Apolipoprotein L1; AT1R: Gene encoding angiotensin II receptor type 1; BMI: Body mass index; CCR2: Gene encoding C-C chemokine receptor type 2; CKD: Chronic kidney disease; CKDEPI: Chronic Kidney Disease Epidemiology Collaboration; CRF: Chronic renal failure; CT: Conservative treatment; DBP: Diastolic blood pressure; DM: Diabetes mellitus; EE: Effect estimate; eGFR: Estimated glomerular filtration rate; eNOS: Gene encoding endothelial nitric oxide synthase; ESRD: End-stage renal disease; GWAS: Genome-wide association studies; HIV: Human immunodeficiency virus; HR: Hazard ratio; HT: Hypertensive; HWE: Hardy-Weinberg equilibrium; KV DOQI: NKF Kidney Disease Outcomes Quality Initiative; MAF: Minor allele frequency; MDRD: Modification of Diet in Renal Disease; MeSH: Medical Subject Headings; MHD: Maintenance hemodialysis; MRF: Moderate renal failure; MTHFR: Gene encoding Methylene tetrahydrofolate reductase; MYH9:
Gene encoding myosin, heavy chain 9; NO: Nitric oxide; NS: Not specified; NT: Normotensive; OR: Odds ratio; PCR-RFLP: Polymerase chain reaction restriction fragment length polymorphism; SAMRC: South African Medical Research Council; SBP: Systolic blood pressure; SNP: Single nucleotide polymorphisms; SRF: Severe renal failure; SSA: Sub-Saharan Africa; UA: Unadjusted; XPD: Gene encoding xeroderma pigmentosum group D; XRCC1: Gene encoding X-ray repair cross-complementing protein 1

\section{Funding}

Financial support, through means of infrastructure, was provided by the South African Medical Research Council (SAMRC). The SAMRC as an organization was not directly involved in the design of the study and collection, analysis, interpretation of data or in writing the manuscript.

\section{Availability of data and materials}

Data sharing is not applicable to this article as no datasets were generated or analysed during the current study. This is a systematic review and all data referred to in this manuscript is publicly available.

\section{Authors' contributions}

$C G, Y Y Y$ and APK contributed to the conception, the design of the study and drafting the manuscript. CG, YYY, IGO, TEM, FJKF and APK critically revised the manuscript for important intellectual content and all co-authors (CG, YYY, IGO, TEM, FJKF, APK) approved the final version of the manuscript.

Ethics approval and consent to participate

Not applicable.

\section{Consent for publication}

Not applicable.

Competing interests

The authors declare that they have no competing interests.

\section{Publisher's Note}

Springer Nature remains neutral with regard to jurisdictional claims in published maps and institutional affiliations.

\section{Author details}

${ }^{1}$ Non-Communicable Diseases Research Unit, South African Medical Research Council, Parow Valley, PO Box 19070, Cape Town, South Africa. ${ }^{2}$ Department of Human Biology, Faculty of Health Sciences, Walter Sisulu University, Mthatha, South Africa. ${ }^{3}$ Department of Medicine, Division of Nephrology and Hypertension, University of Cape Town, Cape Town, South Africa. ${ }^{4}$ Kidney and Hypertension Research Unit, University of Cape Town, Cape Town, South Africa. ${ }^{5}$ Department of Biomedical Sciences, Faculty of Health and Wellness Science, Cape Peninsula University of Technology, Bellville, Cape Town, South Africa. ${ }^{6}$ Faculty of Medicine and Biomedical Sciences, University of Yaounde I, Yaounde, Cameroon. ${ }^{7}$ Medicine Unit, Yaounde University Teaching Hospital, Yaounde, Cameroon.

Received: 14 September 2018 Accepted: 2 October 2018 Published online: 19 October 2018

References

1. Ene-lordache B, Perico N, Bikbov B, Carminati S, Remuzzi A, Perna A, et al. Chronic kidney disease and cardiovascular risk in six regions of the world (ISN-KDDC): a cross-sectional study. Lancet Glob Health. 2016;4(5):e307-19.

2. Ayodele $\mathrm{OE}$, Alebiosu CO. Burden of chronic kidney disease: an international perspective. Adv Chronic Kidney Dis. 2010;17(3):215-24.

3. Jha V, Garcia-Garcia G, Iseki K, Li Z, Naicker S, Plattner B, et al. Chronic kidney disease: global dimension and perspectives. Lancet. 2013; 382(9888):260-72

4. Kiberd BA, Clase CM. Cumulative risk for developing end-stage renal disease in the US population. J Am Soc Nephrol. 2002;13(6):1635-44.

5. Peralta CA, Risch N, Lin F, Shlipak MG, Reiner A, Ziv E, et al. The Association of African Ancestry and Elevated Creatinine in the coronary artery risk development in young adults (CARDIA) study. Am J Nephrol. 2010:31(3): 202-8. 
6. Hsu CY, Lin F, Vittinghoff E, Shlipak MG. Racial differences in the progression from chronic renal insufficiency to end-stage renal disease in the United States. J Am Soc Nephrol. 2003;14(11):2902-7.

7. Wuttke M, Kottgen A. Insights into kidney diseases from genome-wide association studies. Nat Rev Nephrol. 2016;12(9):549-62.

8. Kottgen A, Glazer NL, Dehghan A, Hwang SJ, Katz R, Li M, et al. Multiple loc associated with indices of renal function and chronic kidney disease. Nat Genet. 2009:41(6):712-7.

9. Kottgen A, Pattaro C, Boger CA, Fuchsberger C, Olden M, Glazer NL, et al. New loci associated with kidney function and chronic kidney disease. Nat Genet. 2010:42(5):376-84.

10. O'Seaghdha CM, Fox CS. Genome-wide association studies of chronic kidney disease: what have we learned? Nat Rev Nephrol. 2012;8(2):89-99.

11. Tishkoff SA, Williams SM. Genetic analysis of African populations: human evolution and complex disease. Nat Rev Genet. 2002:3(8):611-21.

12. Bryc K, Velez C, Karafet T, Moreno-Estrada A, Reynolds A, Auton A, et al. Colloquium paper: genome-wide patterns of population structure and admixture among Hispanic/Latino populations. Proc Natl Acad Sci U S A. 2010;107(Suppl 2):8954-61.

13. Tishkoff SA, Reed FA, Friedlaender FR, Ehret C, Ranciaro A, Froment A, et al. The genetic structure and history of Africans and African Americans. Science. 2009;324(5930):1035-44.

14. Moher D, Liberati A, Tetzlaff J, Altman DG. Preferred reporting items for systematic reviews and meta-analyses: the PRISMA statement. PLoS Med. 2009;6(7):e1000097.

15. Bray M, Higgins J, loannidis J, Khoury M, Little J, Manolio T, et al. The HuGENet ${ }^{\text {TM }}$ HuGE Review Handbook, version 1.0. In: Little J, Higgins JPT, editors. The HuGENetTM HuGE review handbook. Version 1.0. 2006. Available at: http://www.med.uottawa.ca/public-health-genomics/web/ assets/documents/hug_review_handbook_v1_o.pdf. Accessed 23 Jan 2017.

16. Pienaar E, Grobler L, Busgeeth K, Eisinga A, Siegfried N. Developing a geographic search filter to identify randomised controlled trials in Africa: finding the optimal balance between sensitivity and precision. Health Inf Libr J. 2011;28(3):210-5.

17. Sagoo GS, Little J, Higgins JP. Systematic reviews of genetic association studies. Human Genome Epidemiol Network PLoS Med. 2009;6(3):e28.

18. Elshamaa MF, Sabry S, Badr A, El-Ahmady M, Elghoroury EA, Thabet EH, et al. Endothelial nitric oxide synthase gene intron4 VNTR polymorphism in patients with chronic kidney disease. Blood Coagul Fibrinolysis. 2011;22(6):487-92.

19. Hanna MOF, Shahin RMH, Meshaal SS, Kostandi IF. Susceptibility and progression of end stage renal disease are not associated with angiotensin II type 1 receptor gene polymorphism. J Rec Signal Transd. 2015;35(5):381-5.

20. Kerkeni M, Letaief A, Achour A, Miled A, Trivin F, Maaroufi K. Endothelial nitric oxide synthetase, methylenetetrahydrofolate reductase polymorphisms, and cardiovascular complications in Tunisian patients with nondiabetic renal disease. Clin Biochem. 2009;42(10-11):958-64.

21. Lahrach H, Essiarab F, Timinouni M, Hatim B, El Khayat S, Er-Rachdi L, et al. Association of apolipoprotein $E$ gene polymorphism with end-stage renal disease and hyperlipidemia in patients on long-term hemodialysis. Ren Fail. 2014;36(10):1504-9.

22. Radwan WM, Elbarbary HS, Alsheikh NM. DNA repair genes XPD and XRCC1 polymorphisms and risk of end-stage renal disease in Egyptian population. Ren Fail. 2015;37(1):122-8.

23. Rezk NA, Zidan HE, Elnaggar YA, Ghorab A. Renalase gene polymorphism and epinephrine level in chronic kidney disease. Appl Biochem Biotechnol. 2015;175(4):2309-17.

24. Elhelbawy NG, Elzorkany KM, Abdelatty AF. Chemokine receptor 2 (CCR2) G190A polymorphism in chronic renal failure patients requiring hemodialysis. Egypt Soc Biochem Mol Biol. 2016;34(1/2):67-76.

25. Elshamaa MF, Sabry SM, El-Sonbaty MM, Elghoroury EA, Emara N, Raafat M, et al. Adiponectin: an adipocyte-derived hormone, and its gene encoding in children with chronic kidney disease. BMC Res Notes. 2012;5:174.

26. Abdallah ES, Sabry D. Renalase gene polymorphisms in end-stage renal disease patients: an Egyptian study. J Amer Sci. 2013;9(1):346-9.

27. Matsha TE, Kengne AP, Masconi KL, Yako YY, Erasmus RT. APOL1 genetic variants, chronic kidney diseases and hypertension in mixed ancestry south Africans. BMC Genet. 2015;16:69.

28. Matsha TE, Masconi K, Yako YY, Hassan MS, Macharia M, Erasmus RT, et al. Polymorphisms in the non-muscle myosin heavy chain gene (MYH9) are associated with lower glomerular filtration rate in mixed ancestry diabetic subjects from South Africa. PLoS One. 2012;7(12):e52529.
29. Tayo BO, Kramer H, Salako BL, Gottesman O, McKenzie CA, Ogunniyi A, et al. Genetic variation in APOL1 and MYH9 genes is associated with chronic kidney disease among Nigerians. Int Urol Nephrol. 2013;45(2): 485-94.

30. Ulasi II, Tzur S, Wasser WG, Shemer R, Kruzel E, Feigin E, et al. High population frequencies of APOL1 risk variants are associated with increased prevalence of non-diabetic chronic kidney disease in the lgbo people from South-Eastern Nigeria. Nephron Clin Pract. 2013;123(1-2):123-8.

31. El-Shal AS, Zidan HE, Rashad NM. Adiponectin gene polymorphisms in Egyptian type 2 diabetes mellitus patients with and without diabetic nephropathy. Mol Biol Rep. 2014;41(4):2287-98.

32. Kao WH, Klag MJ, Meoni LA, Reich D, Berthier-Schaad Y, Li M, et al. MYH9 is associated with nondiabetic end-stage renal disease in African Americans. Nat Genet. 2008:40(10):1185-92.

33. Behar DM, Rosset S, Tzur S, Selig S, Yudkovsky G, Bercovici S, et al. African ancestry allelic variation at the MYH9 gene contributes to increased susceptibility to non-diabetic end-stage kidney disease in Hispanic Americans. Hum Mol Genet. 2010;19(9):1816-27.

34. O'Seaghdha CM, Parekh RS, Hwang SJ, Li M, ttgen AK, Coresh J, et al. The MYH9/APOL1 region and chronic kidney disease in European-Americans. Hum Mol Genet. 2011;20(12):2450-6.

35. Genovese G, Friedman DJ, Ross MD, Lecordier L, Uzureau P, Freedman BI, et al. Association of trypanolytic ApoL1 variants with kidney disease in African Americans. Science. 2010;329(5993):841-5.

36. Tzur S, Rosset S, Shemer R, Yudkovsky G, Selig S, Tarekegn A, et al. Missense mutations in the APOL1 gene are highly associated with end stage kidney disease risk previously attributed to the MYH9 gene. Hum Genet. 2010; 128(3):345-50

37. Genovese G, Friedman DJ, Pollak MR. APOL1 variants and kidney disease in people of recent African ancestry. Nat Rev Nephrol. 2013;9(4): 240-4.

38. Wasser WG, Tzur S, Wolday D, Adu D, Baumstein D, Rosset S, et al. Population genetics of chronic kidney disease: the evolving story of APOL1. J Nephrol. 2012;25(5):603-18.

39. Behar DM, Kedem E, Rosset S, Haileselassie Y, Tzur S, Kra-Oz Z, et al. Absence of APOL1 risk variants protects against HIV-associated nephropathy in the Ethiopian population. Am J Nephrol. 2011;34(5):452-9.

40. Buckley R. Apolipoprotein G1 and G2 variants may partially explain a higher prevalence of lupus-nephritis ESRD in African Americans. MD Conf Express. 2012:10.

41. Cohen DL, Townsend RR. Is it variants in the apolipoprotein I1 gene, or blood pressure control, that predicts progression of nondiabetic hypertensive nephropathy in african americans? J Clin Hypertens. 2013;15(7): 445-6.

42. Colares VS, Titan SMDO, Pereira ADC, Malafronte P, Cardena MM, Santos S, et al. MYH9 and APOL1 gene polymorphisms and the risk of CKD in patients with lupus nephritis from an admixture population. PLoS One. 2014;9(3).

43. Estrella MM, Li M, Tin A, Abraham AG, Shlipak MG, Penugonda S, et al. The association between APOL1 risk alleles and longitudinal kidney function differs by HIV viral suppression status. Clin Infect Dis. 2015; 60(4):646-52.

44. Fine DM, Wasser WG, Estrella MM, Atta MG, Kuperman M, Shemer R, et al. APOL1 risk variants predict histopathology and progression to ESRD in HIVrelated kidney disease. J Am Soc Nephrol. 2012;23(2):343-50.

45. Foster MC, Coresh J, Fornage M, Astor BC, Grams M, Franceschini N, et al. APOL1 variants associate with increased risk of CKD among African Americans. J Am Soc Nephrol. 2013;24(9):1484-91.

46. Roussos L, Flor n C, Carlson J, Svensson PJ, Wallmark A, Ekberg H. Increased prevalence of apolipoprotein E3/E4 genotype among Swedish renal transplant recipients. Nephron. 1999:83(1):25-30.

47. Hsu CC, Kao WH, Coresh J, Pankow JS, Marsh-Manzi J, Boerwinkle E, et al. Apolipoprotein $\mathrm{E}$ and progression of chronic kidney disease. JAMA. 2005; 293(23):2892-9.

48. Choi SW, Kweon SS, Choi JS, Rhee JA, Lee YH, Nam HS, et al. Association between apolipoprotein E polymorphism and chronic kidney disease in the Korean general population: dong-gu study. Kor J Fam Med. 2014:35(6):276-82.

49. Nagase $S$, Suzuki H, Wang $Y$, Kikuchi $S$, Hirayama A, Ueda A, et al. Association of ecNOS gene polymorphisms with end stage renal diseases. Mol Cell Biochem. 2003;244(1-2):113-8. 
50. Noiri E, Satoh H, Taguchi J, Brodsky SV, Nakao A, Ogawa Y, et al. Association of eNOS Glu298Asp polymorphism with end-stage renal disease. Hypertension. 2002;40(4):535-40.

51. Wang Y, Kikuchi S, Suzuki H, Nagase S, Koyama A. Endothelial nitric oxide synthase gene polymorphism in intron 4 affects the progression of renal failure in non-diabetic renal diseases. Nephrol Dial Transplant. 1999;14(12): 2898-902.

52. Bellini MH, Figueira MN, Piccoli MF, Marumo JT, Cendoroglo MS, Neto MC, et al. Association of endothelial nitric oxide synthase gene intron 4 polymorphism with end-stage renal disease. Nephrology (Carlton). 2007; 12(3):289-93.

53. Marson BP, Dickel S, Ishizawa MH, Metzger IF, Izidoro-Toledo T, da Costa BE, et al. Endothelial nitric oxide genotypes and haplotypes are not associated with end-stage renal disease. DNA Cell Biol. 2011;30(1):55-9.

54. Trabulus S, Guven GS, Altiparmak MR, Batar B, Tun O, Yalin AS, et al. DNA repair XRCC1 Arg399GIn polymorphism is associated with the risk of development of end-stage renal disease. Mol Biol Rep. 2012;39(6): 6995-7001.

55. Sanchez-Quinto F, Botigue LR, Civit S, Arenas C, Avila-Arcos MC, Bustamante $C D$, et al. North African populations carry the signature of admixture with Neandertals. PLoS One. 2012;7(10):e47765.

\section{Ready to submit your research? Choose BMC and benefit from:}

- fast, convenient online submission

- thorough peer review by experienced researchers in your field

- rapid publication on acceptance

- support for research data, including large and complex data types

- gold Open Access which fosters wider collaboration and increased citations

- maximum visibility for your research: over $100 \mathrm{M}$ website views per year

At $\mathrm{BMC}$, research is always in progress.

Learn more biomedcentral.com/submissions 